Check for updates

Cite this: Phys. Chem. Chem. Phys., 2018, 20, 19819

Received 24th May 2018, Accepted 14th July 2018

DOI: $10.1039 / \mathrm{c} 8 \mathrm{cp} 03311 \mathrm{k}$

rsc.li/pccp

\title{
Fragmentation of a dioxolanyl radical via nonstatistical reaction dynamics: characterization of the vinyloxy radical by ns time-resolved laser flash photolysis $\uparrow$
}

\author{
Götz Bucher, (D) $\ddagger^{* a}$ Mukul Lal, ${ }^{b}$ Anup Rana ${ }^{b}$ and Michael Schmittel (DD *b
}

\begin{abstract}
The photochemistry of two Barton esters, one derived from a dioxolane carboxylic acid and the other from pivalic acid, was investigated by product analysis and nanosecond laser flash photolysis (LFP). As expected, photolysis of the pivalate ester resulted in formation of the pyridine-2-thiyl and the $t$-butyl radical. Photolysis of the Barton ester of 2,2-dimethyl-1,3-dioxolane-4-carboxylic acid, on the other hand, revealed a complex multi-step fragmentation. In addition to the pyridine-2-thiyl and dioxolanyl radical, we gained evidence for the formation of the vinyloxy radical, $\mathrm{CH}_{2}=\mathrm{CHO}$. The latter was identified in the LFP by its $\pi$-complexes with benzene and diphenylether, its rapid quenching by electron-rich arenes and tri- $n$-butyl tin hydride, and its oxidative power in presence of trifluoroacetic acid as demonstrated by the oxidation of ferrocene to ferrocenium. Formation of $\mathrm{CH}_{2}=\mathrm{CHO}$ can be rationalized via fragmentation of the dioxolanyl radical. As the calculated barriers are too high for the reaction sequence to occur on the LFP time scale, we investigated the fragmentation of the photoexcited Barton ester via Born-Oppenheimer molecular dynamics simulations. In one trajectory, we could observe all reaction steps including ring opening of the dioxolanyl radical, suggesting that the excess energy gained in the ester cleavage and decarboxylation may lead to fragmentation of the hot dioxolanyl radical.
\end{abstract}

\section{Introduction}

Enol and enol ether radical cations ${ }^{1}$ are of considerable significance both to chemical ${ }^{2,3}$ and biological ${ }^{4-7}$ systems. Due to their relevance, several studies directed at elucidating the reactivity of enol ether radical cations via direct kinetic methods such as laser flash photolysis (LFP) have been published. ${ }^{8-11}$ The reactivity of radical cations of free enols, on the other hand, remains to be explored, as only few direct kinetic studies are known. ${ }^{12,13}$ As demonstrated by deuterium kinetic isotope effects, enol radical cations are acidic and thus tend to undergo a facile deprotonation yielding the corresponding vinyloxy radical. ${ }^{13}$

The present work was undertaken with the aim to establish an alternative photochemical route to enol radical cations. It is

\footnotetext{
${ }^{a}$ Lehrstuhl für Organische Chemie II, Ruhr-Universität Bochum, Universitätsstr. 150, 44801 Bochum, Germany

${ }^{b}$ FB 8 (Chemie-Biologie), Organische Chemie I, Universität Siegen, Adolf-Reichwein-Str. 2, 57068 Siegen, Germany. E-mail: schmittel@chemie.uni-siegen.de

$\dagger$ Electronic supplementary information (ESI) available: Synthesis, characterization data, photolysis, EPR, computational data. See DOI: 10.1039/c8cp03311k

\# Current address: WestCHEM, School of Chemistry, University of Glasgow, Joseph-Black-Building, University Avenue, Glasgow G12 8QQ, UK. E-mail: goetz.bucher@glasgow.ac.uk
}

well known that acetals are acid-sensitive functionalities. ${ }^{14}$ We therefore reasoned that the acid-catalyzed ring opening of a radical derived from a cyclic acetonide should represent a potential route to obtain the radical cation of a free enol and/or its conjugated base, the vinyloxy radical. Our approach aimed at the generation of ethenol ${ }^{+} \bullet(\mathbf{1})$, the radical cation of the simplest enol. Explicitly, the intention was to generate 1 by acid-induced fragmentation of the dioxolanyl radical $\mathbf{3}$, which in turn should be readily available from decarboxylation of the carbonyloxy radical 4 (Scheme 1). The latter species was intended to be generated by photolysis of the $N$-hydroxypyridine-2-thione ester ("Barton-ester") 7. As side products, bis-(2-pyridyl)disulfide (6) and acetone (2) are expected to be formed.

For the present study, we employed product analysis, UV-vis spectroscopic monitoring during steady-state irradiation, and laser flash photolysis (LFP) with UV-vis detection. In addition, we applied density functional theory (DFT) including BornOppenheimer molecular dynamic (BOMD) computations to elucidate the reaction pathways occurring in the photolysis. For comparison, we investigated the photochemical decomposition of the $t$-butyl derivative $\mathbf{8}$, which should not undergo fragmentation beyond formation of the $t$-butyl radical (10) (Scheme 2). 


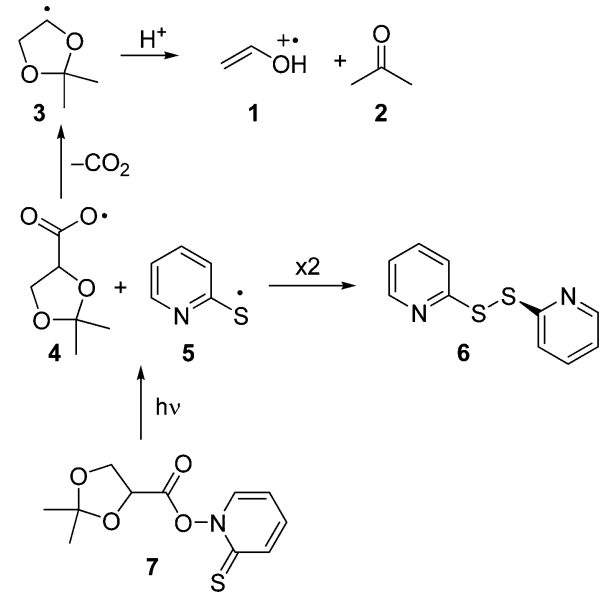

Scheme 1 Possible reaction pathways upon photolysis of $\mathbf{7}$ in acidic medium.

\section{Results and discussion}

\section{Synthesis of the Barton esters}

Barton ester 7 was prepared from mannitol 11, which was first protected as bis-acetonide using acetone in the presence of fused zinc chloride. The resulting bis-acetal 12 was then cleaved by sodium metaperiodate furnishing aldehyde 13. The latter was further oxidized with $\mathrm{KOH} / \mathrm{KMnO}_{4}$ to afford potassium isopropylideneglycerate (14), which was then converted to acid chloride 15 by treatment with oxalyl chloride in the presence of a catalytic amount of pyridine. Finally, the Barton ester 7 was obtained by reacting 15 with the sodium salt of $\mathrm{N}$-2-thiopyridine oxide (Scheme 3). Similarly, Barton ester 8 was synthesized from pivalyl chloride (16) and the sodium salt of $\mathrm{N}$-2-thiopyridine oxide (for details, see $\mathrm{ESI} \dagger$ ).

\section{Stability of 7 towards TFA in benzene solution and complex formation with TFA}

The acetal unit in 7 is an acid-sensitive functionality that may well be affected by acid, in particular in the presence of trace amounts of water serving as nucleophile. ${ }^{14}$ We therefore studied the stability of 7 at equimolar $([7]=[\mathrm{TFA}]=0.1 \mathrm{mM})$ and higher concentrations in dry benzene, which was our choice of solvent for the photolytic experiments (vide infra). After adding an equimolar quantity of TFA to 7 , a very small decrease in absorbance was observed at $\lambda_{\max }=360 \mathrm{~nm}$ (see ESI $\dagger$ ). Further increase in acid concentration not only induced a decrease in the absorbance at $\lambda_{\max }=360 \mathrm{~nm}$ but an additional $12 \mathrm{~nm}$

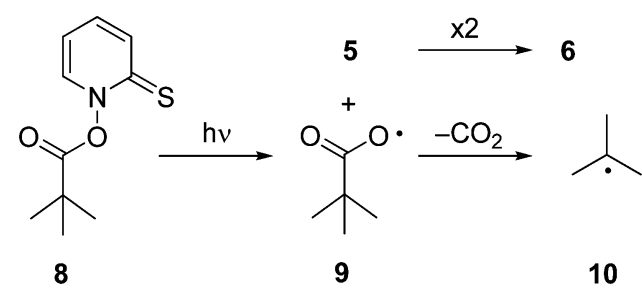

Scheme 2 Reactions in the photolytic decomposition of $\mathbf{8}$.<smiles>CC(C)=O</smiles><smiles>COC(=O)C1COC(C)(C)O1</smiles><smiles>[3H][C@H]1OC(C(=O)Cl)COC1(C)C</smiles>

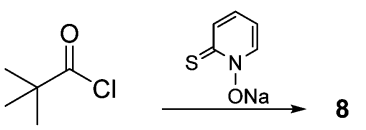

16

Scheme 3 Preparation of Barton esters $\mathbf{7}$ and $\mathbf{8}$

hypsochromic shift to $\lambda_{\max }=348 \mathrm{~nm}$. Nevertheless, the original spectrum of the acid-free 7 was retained after addition of a slight excess of pyridine as base (dilution factor taken into account) to the acidified solution clearly suggesting a fully reversible protonation of the chromophore. TFA addition up to 5 equiv. did not show any substantial decay over time (the absorbance at $360 \mathrm{~nm}$ was 0.646 after 2 min and it was 0.645 after $4 \mathrm{~h}$ ).

The UV-vis spectral changes in the acid addition experiments indicate that protonation of 7 predominantly occurs at the chromophore of the molecule. At low concentration of TFA, the most likely protonation should afford the cation 17 (Scheme 4).

\section{Photolysis in absence and presence of TFA}

The photolysis of 7 in benzene $(c=0.2 \mathrm{mM})$ in the absence of acid using a $300 \mathrm{~W}$ UV lamp was followed by both UV-vis and NMR spectroscopy. The band at $360 \mathrm{~nm}$, characteristic for Barton ester 7, disappeared completely in $60 \mathrm{~s}$. Photolysis of $7(0.49 \mathrm{mM})$ in the presence of 1 equiv. of trifluoroacetic acid (TFA) equally showed a rapid decrease of the absorbance of 7 at $360 \mathrm{~nm}$. Importantly, no absorbing species was detectable in the spectrum up to $800 \mathrm{~nm}$ (Fig. 1).

For preparative purposes the photolyses were conducted at higher concentrations of $7(1.57 \mathrm{mM})$. Product formation was

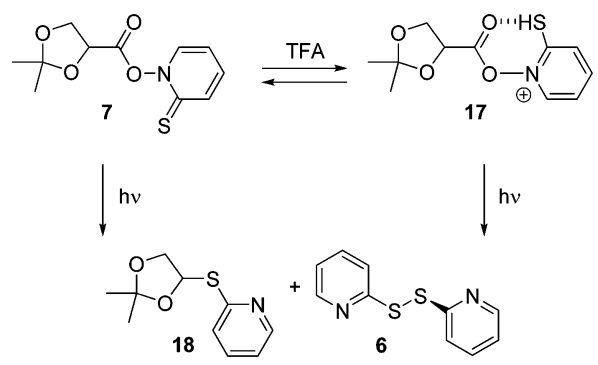

Scheme 4 Protonation and photolysis of $\mathbf{7}$. 

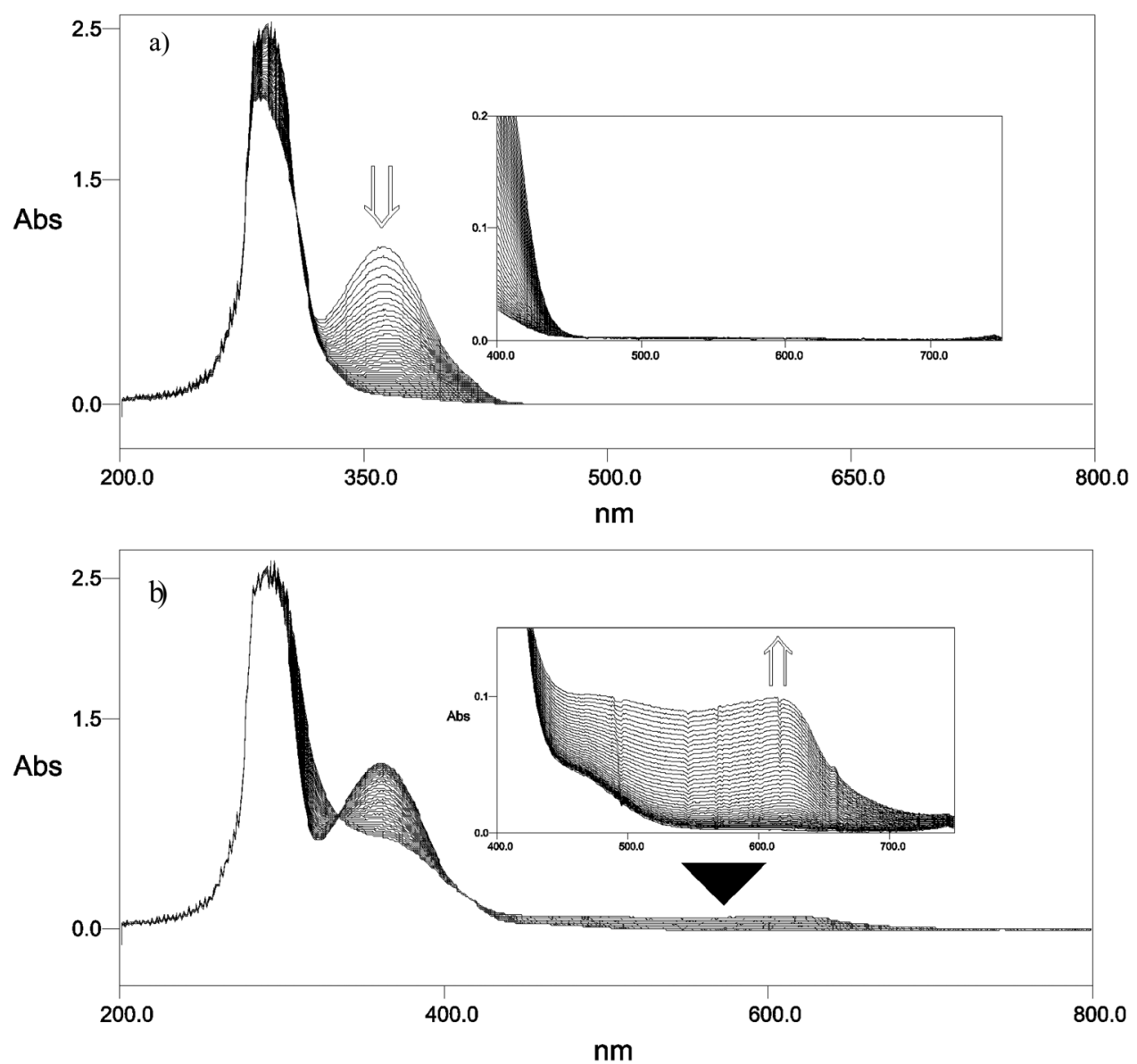

Fig. 1 UV-vis changes observed upon photolysis of Barton ester $\mathbf{7}(490 \mu \mathrm{M})$, (a) in dry benzene containing TFA (490 $\mu \mathrm{M})$ and (b) in presence of both TFA and ferrocene (both $490 \mu \mathrm{M}$ ) in dry benzene $(25 \mathrm{ml}$ ). The UV-vis spectrum is an overlay of spectra measured every second over a period of $90 \mathrm{~s}$.

studied by IR, ${ }^{1} \mathrm{H}$ NMR, ${ }^{13} \mathrm{C}$ NMR and HPLC (for quantification). Notably formation of product $\mathbf{6}$ was increased, most likely because at higher concentrations it arises from the reaction of radical 5 with $7 .{ }^{15}$ HPLC quantification showed that the overall conversion of $\mathbf{7} \rightarrow \mathbf{1 8}$ in the absence of TFA was $89 \%$ (by ${ }^{1} \mathrm{H}$ NMR no further product was detectable) and $59 \%$ in the presence of acid (see ESI $\dagger$ ). Formation of $\mathbf{6}$ was the same for both acid-free and acidic conditions.

\section{Photolysis of 7 in presence of ferrocene.}

Photolysis of 7 ( $0.49 \mathrm{mM}$, dry benzene) in the presence of both TFA and ferrocene (equimolar concentrations) afforded a broad band at $\sim 620 \mathrm{~nm}$ that was assigned to the ferrocenium cation. The photolysis was monitored by UV-vis spectroscopy over a period of $90 \mathrm{~s}$. By adding a strong acid, such as TFA, the photolysis of 7 was slowed down slightly suggesting that protonation of the chromophore stabilizes 7 somewhat against photo-degradation.

A control experiment was conducted with Barton ester 8 . Photolysis of $8(568 \mu \mathrm{M})$ in the presence of an equimolar concentration of ferrocene and TFA showed a decrease of the absorbance at $370 \mathrm{~nm}$ and the formation of 6 and 19. Again, no formation of any long absorbing species above $400 \mathrm{~nm}$ was detectable. Photolysis of $8(568 \mu \mathrm{M})$ in the presence of an equimolar concentration of ferrocene and TFA showed a decrease in the $370 \mathrm{~nm}$ band but no formation of any long absorbing species above $400 \mathrm{~nm}$. Even with 9 equiv. of TFA (5.19 mM) no formation of any long absorbing species was observed (see ESI $\dagger$ ).

The above experiments with 8 in presence of TFA and ferrocene suggest that the putative oxidants $\mathbf{6}^{+} \boldsymbol{}$ or protonated $5 \cdot \mathrm{H}^{+}$are either not formed during the photolytic conditions or have very short transient lifetimes insufficient for intermolecular electron transfer with ferrocene. Laser flash photolysis of 6 has been carried out by Osamu Ito et al. in various solvents, ${ }^{16}$ but without any evidence for $\mathbf{6}^{+}$or $\mathbf{5} \cdot \mathrm{H}^{+}$. Thus, the finding of ferrocenium formation with 7, TFA, ferrocene and light suggests that another, yet unknown strong oxidant is formed in the photolysis that is a result of the dioxolane's follow-up reactions.

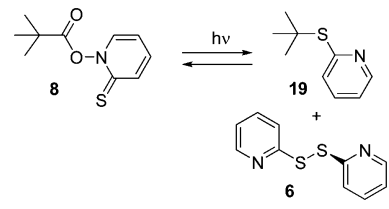

As Barton esters are known to be prone to decomposition in radical chain reactions, a plausible mechanism for the formation of $\mathbf{1 8}$ (or 19) appears to be the attack of radical 3 (or 10) onto the sulfur atom in 7 (or 8), which would eventually release another equivalent of radical 3 (or 10) to continue the radical 
chain process (vide infra). Disulfide 6 in turn could be formed by dimerization of radical 5 or by radical-induced decomposition of 7 (or 8), ${ }^{15}$ both mechanisms explaining increased formation of 6 at higher concentrations of 7 (or 8).

In summary, the observations indicate that in the presence of TFA and light an oxidizing species is formed in the solution from 7 that is derived from the dioxolane unit. While the data would be consistent with formation of ethenol radical cation (1) as hypothesized in Scheme 1, we note that the oxidation of ferrocene could also be due to reactions of other short-lived oxidants.

\section{Laser flash photolysis}

Experiments with 7 and 8 employing LFP with UV-vis detection were performed employing the third harmonic of a Nd-YAG laser $\left(\lambda_{\text {exc }}=355 \mathrm{~nm}\right)$ as excitation light source in combination with benzene as solvent.

LFP of pivalate $8(c=0.1 \mathrm{mM})$ in benzene solution gave the transient spectrum shown in Fig. 2. We observed a single transient with $\lambda_{\max } \sim 480$ and ca. $570 \mathrm{~nm}$ (second order decay, half-life in the $\mu$ s range), which we assign to the pyridine 2-thiyl radical (5), complexed to a benzene molecule. Our spectrum agrees well with the spectrum reported by Aveline, Kochevar and Redmond, ${ }^{15}$ using benzene as solvent, whereas in THF solution, radical 5 has been reported to show an absorption maximum with $\lambda_{\max }=490 \mathrm{~nm} .^{16} \pi$-Complex formation with benzene is predicted (TD-B3LYP/6-311++G(d,p)(pcm,benzene)// M06-2X/cc-pVTZ)(pcm,benzene) to result in a broadening of the spectrum with two absorption maxima at $\lambda_{\max }=425$ and $556 \mathrm{~nm}$, in reasonable agreement with the experimental observation (for the calculated absorption spectrum of a complex of 5 and benzene, see the ESI $\dagger$ ). Adding $0.5 \mathrm{mM}$ TFA did not change the transient spectrum. In agreement with the absorption maxima of the precursor, there is a bleach at $\lambda=295$ and $375 \mathrm{~nm}$. Interestingly, at both wavelengths we observed an apparent recovery of the signal, which occurred with a first-order rate constant $k=7.4 \times 10^{4} \mathrm{~s}^{-1}$, corresponding to $\tau=13.5 \mu \mathrm{s}$. Usually, bleach and recovery like this is observed, if a long-lived triplet

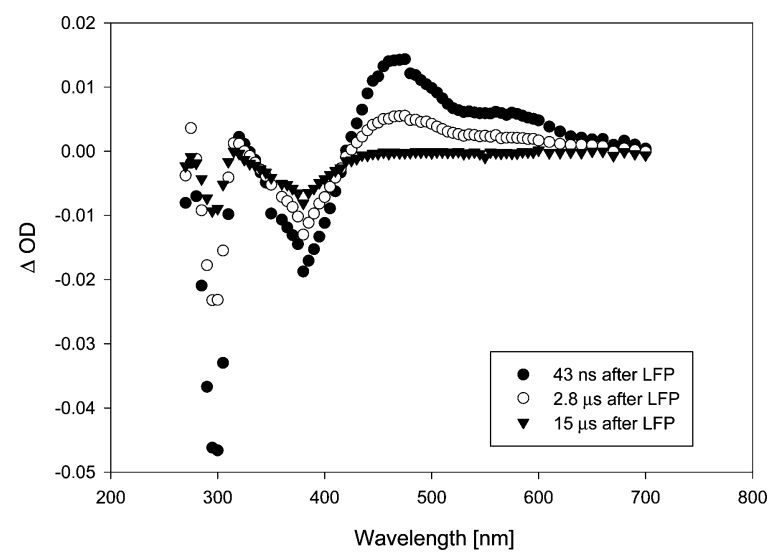

Fig. 2 Transient absorption spectra, monitored after different time intervals following LFP ( $\lambda_{\text {exc }}=355 \mathrm{~nm}$, laser attenuated to ca. $20 \mathrm{~mJ}$ per pulse) of a $0.1 \mathrm{mM}$ solution of $\mathbf{8}$ in benzene, purged with argon.

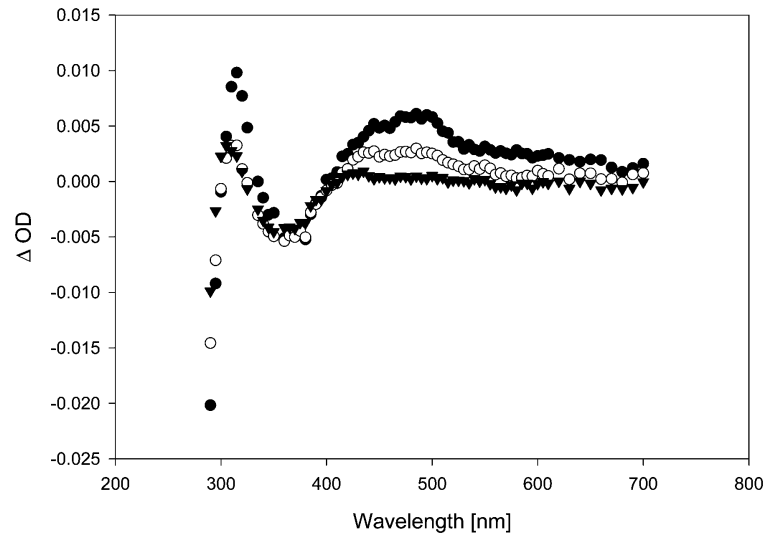

Fig. 3 Transient spectra, observed upon LFP ( $\lambda_{\text {exc }}=355 \mathrm{~nm}, 120 \mathrm{~mJ}$ per pulse) of $7(0.1 \mathrm{mM})$ in benzene, purged with argon. Black circles: $400 \mathrm{~ns}$ after LFP. White circles: $3.4 \mu$ s after LFP. Black triangles: $15 \mu$ s after LFP.

excited state returns to the ground state and the precursor concentration thus is replenished. This certainly cannot be the case here. We therefore suggest that the bleach and recovery reflects the reaction of the $t$-butyl radical (which we do not observe directly) with the precursor $\mathbf{8}$, yielding a species that absorbs at a similar place as $\mathbf{8}$, yet stronger.

LFP of acetonide 7 gave significantly weaker transient signals. A larger number of different transient species observed conveyed a much more complex mechanistic picture. Fig. 3 shows the transient spectrum observed upon LFP of a $0.1 \mathrm{mM}$ solution of 7 in benzene, purged with argon. We observed a transient A decaying according to 2 nd order kinetics $\left(\lambda_{\max }=445\right.$ and $485 \mathrm{~nm}$ ) that is again assigned to a complex of thiyl radical 5 with benzene. ${ }^{16}$ Additionally, a transient $\mathbf{B}$ with $\lambda_{\max }=315 \mathrm{~nm}$ and a much shorter lifetime (1st order: $\tau=170 \mathrm{~ns}$ ) was observed (Fig. 3). If the laser power was reduced to $c a$. $20 \mathrm{~mJ}$ per pulse, we again observed growth or recovery at the absorption maxima of the precursor. This reaction took place with a lifetime $\tau=170 \mathrm{~ns}$. On a yet shorter time-scale, we detected another transient $\mathbf{C}$, showing a $\lambda_{\max }=$ $500 \mathrm{~nm}$ that appears to be formed in a monophotonic process (the plot of transient intensity vs. laser power is linear, see Fig. S6, ESI $\dagger$ ). Its lifetime is extremely short ( $\tau=34 \mathrm{~ns}$ ) (Fig. 4).

Addition of $0.03 \%$ TFA to the solution did not affect the transient spectra of $\mathbf{A}, \mathbf{B}$ or $\mathbf{C}$. The lifetimes of the three transients also did not change. We could, however, observe certain changes in the reactivity of transient $\mathbf{C}$. This species turned out to be quenched by electron-rich aromatic quenchers such as anisole at a rate that was close to or at the diffusioncontrolled limit (Fig. 5). Adding TFA further increased the reactivity slightly. Table 1 shows quenching rate constants measured both in the presence and in the absence of TFA.

In the presence of TFA, the quenching rate constants turned out to be consistently slightly higher than in the absence of TFA. This effect was particularly obvious in the case of anisole as quencher. When diphenylether (DPE) was added, the transient lifetime measured at $\lambda=500 \mathrm{~nm}$ increased in the absence of TFA ( $\tau=90 \mathrm{~ns}$ in the presence of $0.08 \%$ diphenylether), and decreased in the presence of TFA. In the absence of TFA, we 


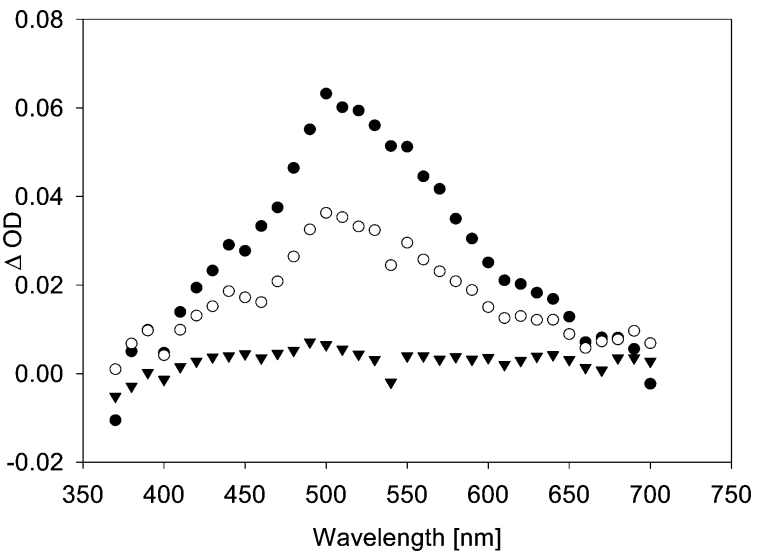

Fig. 4 Transient spectra, observed upon LFP $\left(\lambda_{\text {exc }}=355 \mathrm{~nm}, 120 \mathrm{~mJ}\right.$ per pulse) of $\mathbf{7}(0.1 \mathrm{mM})$ in benzene, purged with argon. Black circles: $14 \mathrm{~ns}$ after LFP. White circles: 34 ns after LFP. Black triangles: 150 ns after LFP.

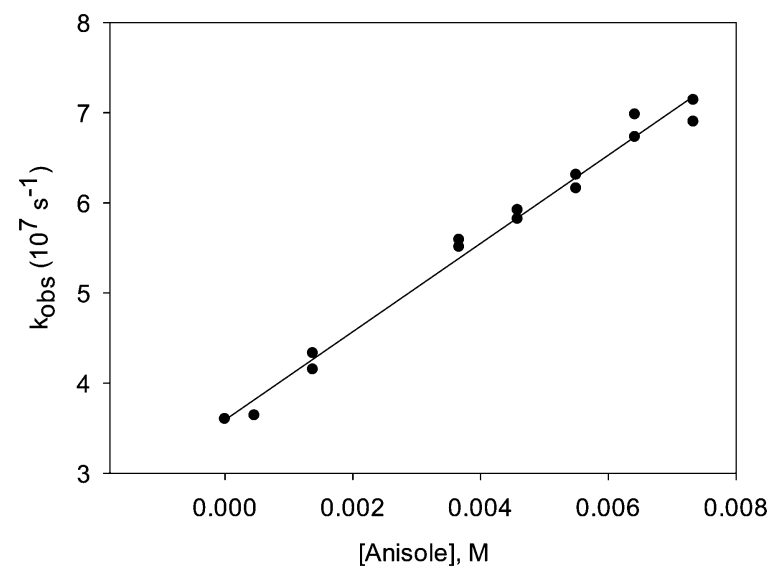

Fig. 5 Plot of the transient decay rate constant, measured at $\lambda=500 \mathrm{~nm}$ after LFP $\left(\lambda_{\text {exc }}=355 \mathrm{~nm}\right.$ ) of $\mathbf{7}$ in benzene, purged with argon, versus the concentration of anisole. The straight line represents a linear fit to the data.

also observed a bathochromic shift in $\lambda_{\max }$ (from $\lambda_{\max }=500 \mathrm{~nm}$ in the absence of DPE to a double maximum at $c a .500$ and $630 \mathrm{~nm}$ in the presence of DPE), and the transient absorption spectrum became more intense and much broader (Fig. 6). Whether the growth ( $\tau=7 \mathrm{~ns}$ ) that is seemingly resolved during the initial stages of the transient trace (Fig. 7, upper trace) is real or not is uncertain, as this growth lifetime is very close to the rise time of our LFP detector. ${ }^{17}$

Considering the three different transient species observed, the assignment of $\mathbf{A}$ to thiyl radical $\mathbf{5}$ is straightforward based

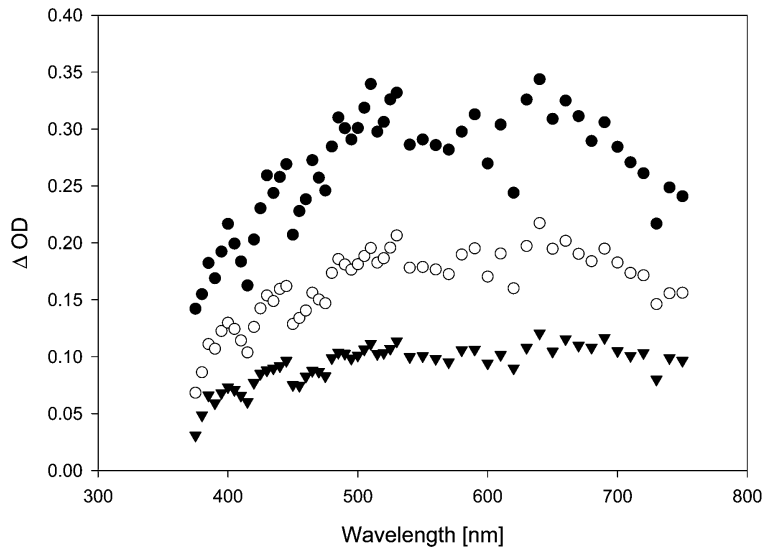

Fig. 6 Transient spectra, observed upon LFP $\left(\lambda_{\text {exc }}=355 \mathrm{~nm}, 120 \mathrm{~mJ}\right.$ per pulse) of $7(0.1 \mathrm{mM})$ in benzene containing $0.08 \%$ diphenylether, purged with argon. Black circles: 25 ns after LFP. White circles: 80 ns after LFP. Black triangles: 165 ns after LFP.

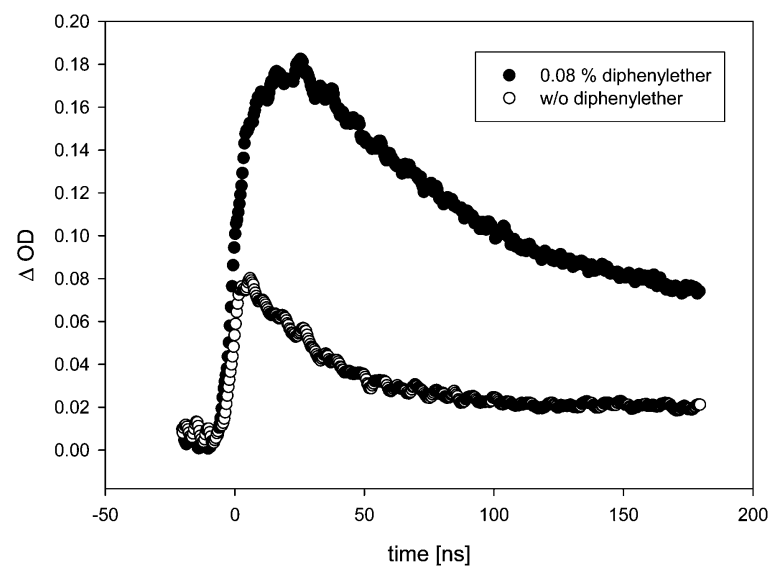

Fig. 7 Transient traces, monitored at $\lambda=500 \mathrm{~nm}$ upon LFP $(355 \mathrm{~nm})$ of 7 in benzene. Bottom trace: Without diphenylether. Top trace: In the presence of $0.08 \%$ diphenylether.

on a comparison with literature data, ${ }^{16}$ as well as a comparison with a calculated spectrum of the complex 5.benzene. The identity of transients $\mathbf{B}\left(\lambda_{\max }=315 \mathrm{~nm}, \tau=170 \mathrm{~ns}\right)$ and $\mathbf{C}$ $\left(\lambda_{\max }=500 \mathrm{~nm}, \tau=34 \mathrm{~ns}\right.$ ), however, still needs to be discussed. In the experiments with pivalate 8 , we observed a growth or recovery in the absorption bands of the precursor that occurred with a lifetime $\tau=13.5 \mu \mathrm{s}$. As there is no transient observed decaying with this lifetime, it appears reasonable to attribute this growth to a reaction of the $t$-butyl radical, which is not

Table 1 Rate constants for quenching of transient $\mathbf{C}$ in the absence and presence of TFA

\begin{tabular}{lll}
\hline Quencher & Rate constant in benzene & Rate constant in benzene $+0.03 \%$ TFA \\
\hline $1,2,3$-Trimethoxybenzene & $(8.2 \pm 0.8) \times 10^{9} 1 \mathrm{~mol}^{-1} \mathrm{~s}^{-1}$ & $(1.1 \pm 0.1) \times 10^{10} 1 \mathrm{~mol}^{-1} \mathrm{~s}^{-1}$ \\
Anisole & $(4.9 \pm 0.5) \times 10^{9} 1 \mathrm{~mol}^{-1} \mathrm{~s}^{-1}$ & $(8.9 \pm 0.9) \times 10^{9} 1 \mathrm{~mol}^{-1} \mathrm{~s}^{-1}$ \\
Diphenylether & Lifetime increases & $(1.4 \pm 0.1) \times 10^{10} 1 \mathrm{~mol}^{-1} \mathrm{~s}^{-1}$ \\
Toluene & No quenching observed & No quenching observed \\
Tri- $n$-butylstannane & $(1.6 \pm 0.2) \times 10^{9} 1 \mathrm{~mol}{ }^{-1} \mathrm{~s}^{-1}$ & Not measured \\
Cyclohexane & No quenching observed & No quenching observed
\end{tabular}




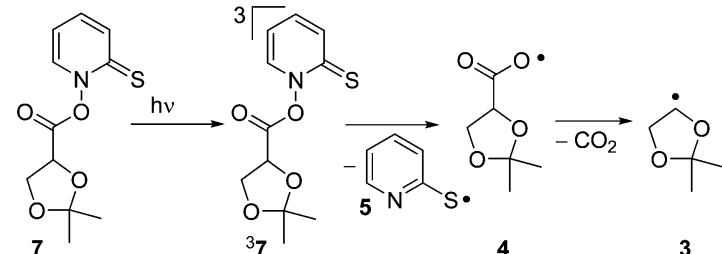

Scheme 5 Possible intermediates in the photochemical fragmentation of Barton ester $\mathbf{7}$ in the absence of TFA.

expected to be detectable in our experiments owing to the lack of a good chromophore absorbing at $\lambda>300 \mathrm{~nm}$.

While we can only speculate about the nature of this reaction, our possible candidate for transient $\mathbf{B}$ is the dioxolanyl radical 3. TD-DFT calculations (TD-B3LYP/6-31 + G*//B3LYP/ $6-31 \mathrm{G}^{*}$ ) reveal that this radical in the gas phase should have a longest-wavelength transition at $\lambda=302 \mathrm{~nm}$, which should not be particularly intense $(f=0.0016)$. Thus there is qualitative agreement between the calculated absorption maximum of 3 and the absorption maximum of $\mathbf{B}$. Given the fact, that formation of thioether $\mathbf{1 8}$ as a major product is strongly indicative of the intermediacy of $\mathbf{3}$, the assignment appears reasonable. Its rather short lifetime ( $\tau=170 \mathrm{~ns}$ ) likely stems from a rapid reaction with the precursor. Given a diffusion-controlled reaction between 3 and 7 , a sub- $\mu$ s lifetime would be expected for 3 in the submillimolar concentration range employed for precursor 7 .

Assigning the short-lived transient $\mathbf{C}$ is less straightforward. Possible candidates include a triplet excited state of precursor 7 , carbonyloxy radical 4 , the ring-opened radicals 20 or 21 , and the vinyloxy radical 22 (Scheme 5 and Fig. 8).

As far as the triplet-excited Barton ester ${ }^{3} 7$ or carbonyloxy radical $\mathbf{4}$ are concerned, the barriers for fragmentation are expected to be very small. In fact, in both cases DFT optimizations resulted in either spontaneous $\mathrm{N}-\mathrm{O}$ bond cleavage ( ${ }^{3}$, M06-2X/cc-pVDZ) or in a very small barrier to decarboxylation (4, M06-2X/cc-pVQZ: $\left.\Delta U^{\ddagger}=0.8 \mathrm{kcal} \mathrm{mol}^{-1}\right)$. Born-Oppenheimer molecular dynamics simulations (M06-2X/cc-pVDZ) also in both cases resulted in $\mathrm{C}-\mathrm{C}$ cleavage (4) or $\mathrm{N}-\mathrm{O}$ cleavage followed by C-C cleavage ( ${ }^{3} 7$ ), within a few femtoseconds each. Hence, an assignment of transient $\mathbf{C}$ to either species does not appear to represent a viable option. Among the remaining

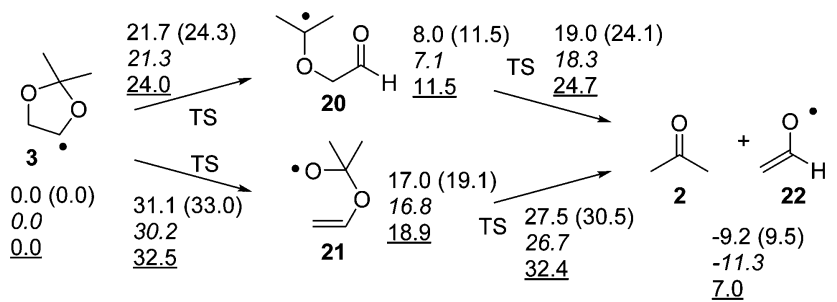

Fig. 8 Calculated (M06-2X/cc-pVQZ or CCSD(T)/cc-pVTZ//M06-2X/ccpVQZ) energies (in $\mathrm{kcal} \mathrm{mol}^{-1}$ ) for stationary points in the fragmentation of 3, relative to $3=0.0 \mathrm{kcal} \mathrm{mol}^{-1}$. Normal font: $\mathrm{M} 06-2 \mathrm{X}$ free energies, gas phase; in brackets: M06-2X electronic energies, gas phase. Italics: M06-2X free energies, benzene solution $(\mathrm{scrf}=\mathrm{pcm})$. Underlined: $\operatorname{CCSD}(\mathrm{T})$ electronic energies, gas phase. radical species 20-22, the vinyloxy radical (or formylmethyl radical) 22 represents the most likely assignment, as DFT calculations indicate that the barrier for decay of both 20 and 21 is smaller than the barrier for their formation, meaning that 20 or $\mathbf{2 1}$ should normally only be present in quasistationary concentration (Fig. 8). We note that the results obtained using the M06-2X/cc-pVQZ method are in excellent agreement with the results from the $\operatorname{CCSD}(\mathrm{T})$ single point energy calculations. Over all, the fragmentation of $\mathbf{3}$ is predicted to be endothermic, but exergonic (at $T=298 \mathrm{~K}$ ), hence entropy-driven.

In the gas phase, the longest-wavelength absorption maximum of 22 is calculated (TD-B3LYP/6-31+G*) at $\lambda_{\max }=271 \mathrm{~nm}$. However, if $\pi$-complexation to benzene or DPE is taken into account, additional weak long-wavelength CT bands appear at $\lambda_{\max }=468 \mathrm{~nm}$ ( $\pi$-complex with benzene) or $\lambda_{\max }=464$ and $689 \mathrm{~nm}$ ( $\pi$-complex with DPE) (all values TD-UB3LYP/ aug-cc-pVTZ//UM062X/cc-pVQZ). Hence, with these CT bands, the calculated UV-vis spectra of the vinyloxy/arene complexes qualitatively match the experimental transient spectra shown in Fig. 4 and 6, including the double maximum observed for the DPE complex. Fig. 9 shows a juxtaposition of the calculated $v s$. the experimental spectrum of 22.DPE, recorded in the presence of $0.08 \%$ DPE.

As far as the quenching reactions of the short-lived transient C are concerned, we note that both the high reactivity towards electron-rich arenes and the increase in reactivity upon addition of TFA would also be consistent with an assignment to the vinyloxy radical (22). A hydrogen-bridged complex of 22 with TFA would be very similar to a free ethenol radical cation in both structure and likely also oxidative power. Such complex would explain the pronounced reactivity of 22 in acidic medium, in particular its capability to rapidly react with DPE or Fc, whereas no reaction (or an increase in lifetime by complex formation) was observed in the absence of TFA.

In the LFP of $\mathbf{7}$ and 8, at low laser powers, an apparent recovery was observed at the wavelength of the precursor absorption band. The kinetics of this recovery in case of 7 matched the kinetics of the decay of radical 3, monitored at $\lambda=315 \mathrm{~nm}$. The fact that the recovery in case of the LFP of 7 was only observed when the laser power was reduced would be consistent with an assignment of this transient process to a reaction of the precursor Barton esters 7 and $\mathbf{8}$, as use of high laser power would result in complete bleaching of the precursor, so that its subsequent radical chain reactions would be suppressed. It cannot be the growth of thioethers 18 or 19 that is resolved here (Scheme 6), as the UV-vis spectrum of the very similar 2-methylthiopyridine, which may serve as a model system, has neither been reported ${ }^{18 a}$ nor is expected to show absorption around $\lambda_{\max }=390 \mathrm{~nm}$. Likewise, the UV-vis spectrum of di-2-pyridyldisulfide (6) has not been reported to show absorption at this wavelength. ${ }^{18 b}$ This hypothesis would also be consistent with the observation that the lifetime of the $t$-butyl radical (10) in the presence of $0.1 \mathrm{mmol} \mathrm{L}^{-1}$ of 7 is $\tau=13.5 \mu \mathrm{s}$, whereas the lifetime of $\mathbf{3}$ under analogous conditions $\left([8]=0.1 \mathrm{mmol} \mathrm{L}^{-1}\right)$ is only $\tau=170 \mathrm{~ns}$. The rate constant of the reaction of $\mathbf{8}$ with the sterically hindered radical $\mathbf{1 0}$ can be 


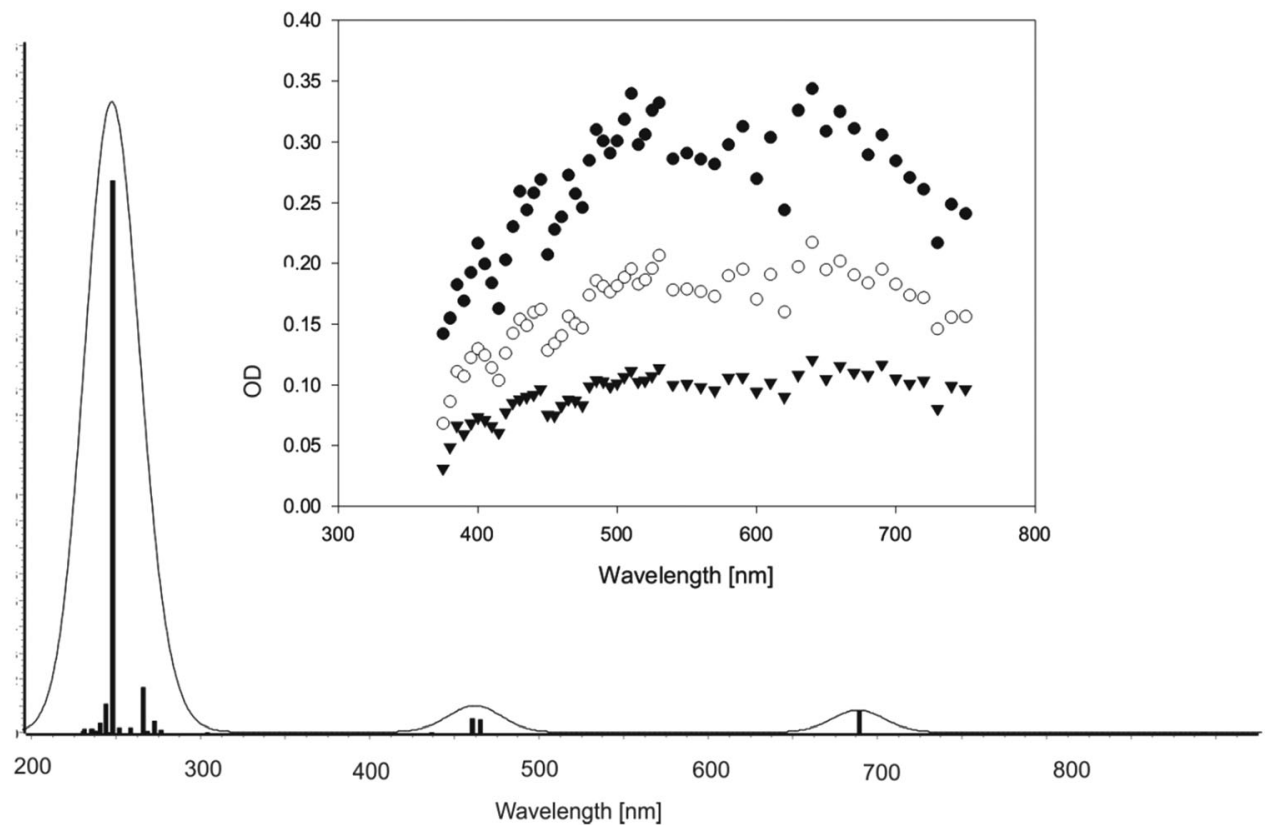

Fig. 9 Bottom: Calculated UV/vis spectrum of complex 22.DPE (TD-UB3LYP/aug-cc-pVTZ//UM062X/cc-pVQZ). Inset: Experimental transient spectrum, observed after LFP $(355 \mathrm{~nm})$ of 7 in benzene $(1 \mathrm{~atm}$. Ar) in the presence of $0.08 \%$ DPE. Black circles: $25 \mathrm{~ns}$ after LFP. White circles: $80 \mathrm{~ns}$ after LFP. Black triangles: 165 ns after LFP.

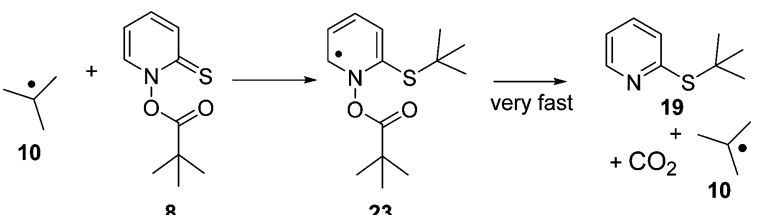

Scheme 6 Reaction pathway in the reaction of Barton ester 7 with radical 10

expected to be smaller than the rate constant of the analogous reaction of 7 with the more accessible radical 3. Reactions of free radicals like $\mathbf{3}$ or $\mathbf{1 0}$ with Barton esters are expected to proceed via addition to the sulfur atom of the reactive $\mathrm{C}=\mathrm{S}$ bond, followed by cleavage of the rather weak $\mathrm{N}-\mathrm{O}$ bond in adducts such as $\mathbf{2 3}$ (Scheme 6).

It is noted that the barrier for cleavage of the radical adduct 23 is expected to be very small. At the M06-2X/6-311++G(2df,p) (pcm,benzene) level of theory, a relaxed surface scan systematically stretching the $\mathrm{N}-\mathrm{O}$ bond in $\mathbf{2 3}$ resulted in an increase in energy of only $0.8 \mathrm{kcal} \mathrm{mol}^{-1}$ required to reach a point where fragmentation into 19, 10 and $\mathrm{CO}_{2}$ occurred. Hence, any free radical intermediate formed along the reaction coordinate linking 8/10 with $\mathbf{1 0 / 1 9}$ will be extremely short-lived. We will therefore leave the assignment of the species responsible for the growth at $\lambda=390 \mathrm{~nm}$ open at present, merely noting that kinetic data indicate that this species results from reaction of radicals $\mathbf{3 / 1 0}$ with Barton esters $\mathbf{7 / 8}$. The results of an in-depth computational study on reactions of Barton esters with free radicals will be published in due course.

Notably, we have been able to detect radical 3 in the photolysis of 7 in benzene by time resolved EPR (see ESI $\dagger$ ). Radical 3, generated by hydrogen abstraction or photoionization, had been detected earlier by EPR spectroscopy and had not demonstrated any fragmentation at ambient temperature. ${ }^{19,20}$ The barriers for its fragmentation are significant - even the more favourable pathway via radical 20 bears a $21.7 \mathrm{kcal} \mathrm{mol}^{-1}$ free energy of activation in the initial step (see Fig. 8), which would normally make a fragmentation on the ps timescale completely impossible. Our observation of the vinyloxy radical (22), however, necessitates such a rapid fragmentation. The $\mathrm{BDE}$ of the $\mathrm{N}-\mathrm{O}$ bond in Barton esters is small, estimates range between 16 and $28 \mathrm{kcal} \mathrm{mol}^{-1}$. 21,22 Given the fact that a $355 \mathrm{~nm}$ photon carries an energy of $82 \mathrm{kcal} \mathrm{mol}^{-1}$, and that the decarboxylation of 4 is exothermic by $35 \mathrm{kcal} \mathrm{mol}^{-1}$ (M06-2X/cc-pVQZ), a sizeable excess energy of at least $90 \mathrm{kcal} \mathrm{mol}^{-1}$ remains for the complete photoinduced fragmentation of 7 into thiyl radical 5 , dioxolanyl radical 3 , and $\mathrm{CO}_{2}$. Even if this excess energy is evenly spread over all vibrational degrees of freedom in all three fragments, sufficient energy ( $c a .66 \mathrm{kcal} \mathrm{mol}^{-1}$ ) will remain in 3 to potentially result in rapid fragmentation. In order to gain further evidence for potential nonstatistical reaction dynamics ${ }^{23}$ in the fragmentation of 3, we performed Born-Oppenheimer molecular dynamic (BOMD) simulations at the UB3LYP-D3(BJ)/6-31G* level. Four possible conformers of 7 (Fig. 10) were considered with $7 \mathrm{c}$ being the most stable one. Quasiclassical trajectories were initialized from normal mode sampling of $7 \mathrm{c}$ in the $\mathrm{T}_{1}$ state to approximate a quantum mechanical Boltzmann distribution of the vibrational levels at $298 \mathrm{~K}$. The overlay of the sampled geometries is shown in Fig. 11. A total of 98 trajectories were initiated from the sampled structures.

For all the trajectories, $\mathrm{N}^{1}-\mathrm{O}^{2}$ and $\mathrm{C}^{3}-\mathrm{C}^{4}$ (Fig. 12) bonds cleave within the fs time scale. The average time to break the $\mathrm{N}^{1}-\mathrm{O}^{2}$ bond, as defined by lengthening of the same beyond 


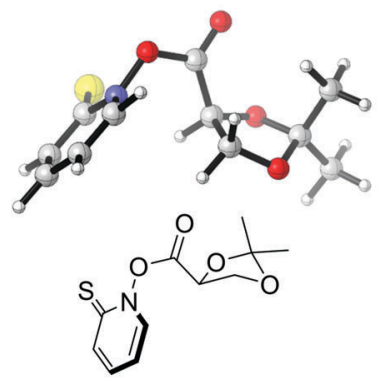

$7 \mathbf{a}$

6.8

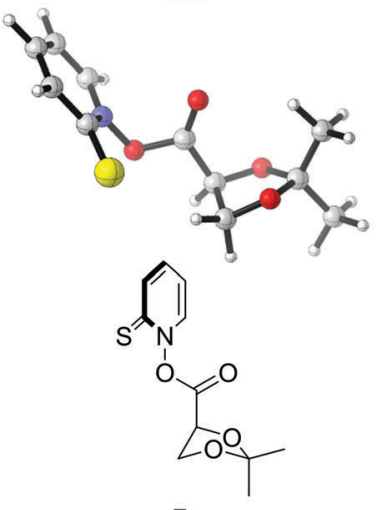

$7 \mathrm{c}$
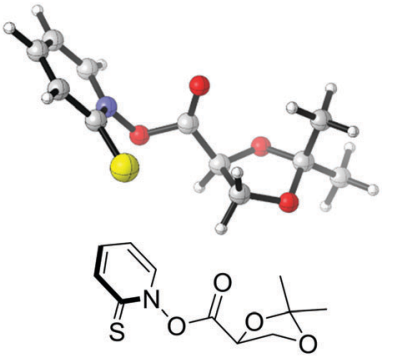

$7 \mathrm{~b}$

0.3
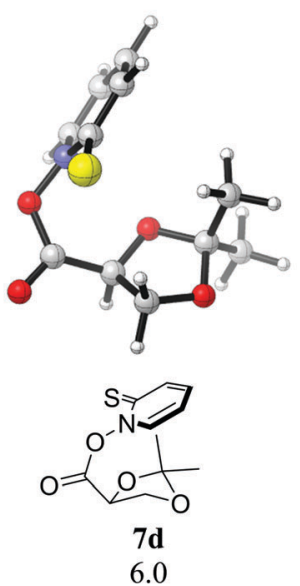

Fig. 10 Conformers of 7. Numerical values are relative free energies (in kcal mol${ }^{-1}$ ) at $25^{\circ} \mathrm{C}$ (B3LYP-D3(BJ)/6-31G* level).

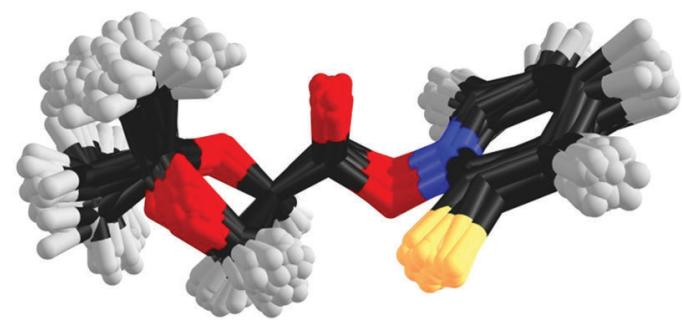

Fig. 11 Overlay of the sampled structures of $7 c$ in the $T_{1}$ state.

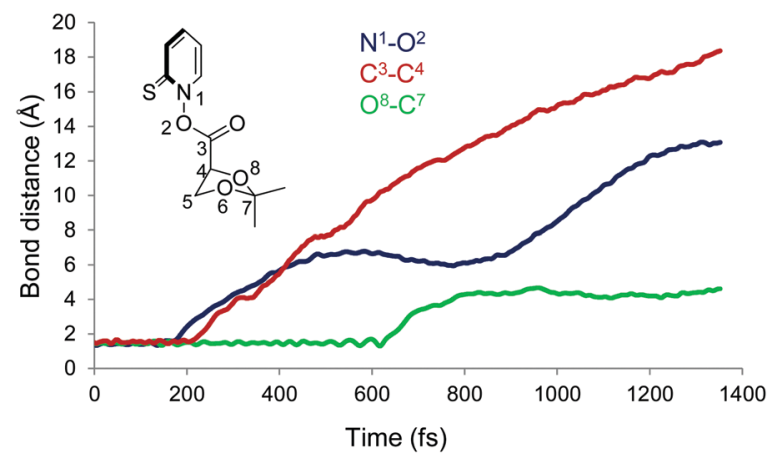

Fig. 12 Effective trajectory yielding 20.

$1.60 \AA$, is 196 fs whereas the $C^{3}-C^{4}$ bond cleaves at 276 fs, considering a bond distance larger than $1.90 \AA$ A. Accordingly, the average time lag between the two bond cleavage events is $80 \mathrm{fs}$.
The minimum time required to cleave the $\mathrm{N}^{1}-\mathrm{O}^{2}$ bond is $23 \mathrm{fs}$ while the maximum time is 787 fs. Interestingly, the sluggish trajectory took only 45 fs to cleave the second bond. Although all the trajectories ended up eliminating $\mathrm{CO}_{2}$ within 1121 fs, only one went further to cleave the third bond $\left(\mathrm{O}^{8}-\mathrm{C}^{7}\right)$ dynamically. It took a total 630 fs to disrupt all three bonds. Thereafter, the dihedral angle $\mathrm{C}^{4}-\mathrm{C}^{5}-\mathrm{O}^{6}-\mathrm{C}^{7}$ started to rotate but the $\mathrm{C}^{5}-\mathrm{O}^{6}$ bond did not break within the simulation time limit of 1352 fs. Thus, the finding indicates that the $\mathrm{C}^{5}-\mathrm{O}^{6}$ bond breaking is the rate determining step, in contrast to the result obtained via the calculated barrier heights ( $c f$. Fig. 8).

\section{Conclusions}

Photolysis of dioxolane-carboxylic acid Barton ester 7 results in formation of the vinyloxy radical 22, which was detected via ns LFP as its benzene or diphenylether $\pi$-complexes. Its formation on a ps timescale can only be rationalized by invoking contribution of dynamic effects, for which evidence could also be gained by performing Born-Oppenheimer molecular dynamics simulations. The vinyloxy radical 22 is a potent oxidant, as shown by very rapid quenching by electron-rich arenes. Addition of trifluoroacetic acid further increases its oxidative power, and the complex of $\mathrm{CH}_{2}=\mathrm{CHO}$ with $\mathrm{CF}_{3} \mathrm{COOH}$ essentially behaves like the radical cation of ethenol.

\section{Experimental part and computational methodologies}

Nanosecond laser flash photolysis. The LFP set-up used in these experiments has previously been described. ${ }^{17}$ Solutions of 7 and 8 in benzene $(0.1 \mathrm{mM})$ were purged with 1 atm. of Ar, and photolyzed $\left(\lambda_{\text {exc }}=355 \mathrm{~nm}, 10 \mathrm{~ns}, 70 \mathrm{~mJ}\right.$ pulse ${ }^{-1}$ ) using a flow cell to avoid precursor depletion and product build-up.

Computational methods. All DFT calculations were performed using the Gaussian09 suite of programs. ${ }^{23}$ All stationary points were characterized as minima or transition structures by performing a vibrational analysis. DFT methods used include the M06-2X and B3LYP functionals, employing both Pople- and Dunning-type basis sets. $^{24-28}$ The effect of solvation by benzene was taken into account using a polarizable continuum method. ${ }^{29,30}$

\section{Conflicts of interest}

There are no conflicts to declare.

\section{Acknowledgements}

The authors thank both the University of Glasgow (G. B.) and Universität Siegen (A. R.) for CPU time on the local clusters (Glasgow High Performance Cluster, HorUS Cluster). We are indebted to Dr Dirk Grote (Ruhr-Universität Bochum) for measuring the EPR spectrum. 


\section{References}

1 M. Schmittel, M. Lal, R. Lal, M. Röck, A. Langels, Z. Rappoport, A. Basheer, J. Schlirf, H.-J. Deiseroth, U. Flörke and G. Gescheidt, A comprehensive picture of the one-electron oxidation chemistry of enols, enolates and $\alpha$-carbonyl radicals: Oxidation potentials and characterization of radical intermediates, Tetrahedron, 2009, 65, 10842.

2 Y. Yamaguchi, Y. Okada and K. Chiba, Understanding the reactivity of enol ether radical cations: investigation of anodic four-membered carbon ring formation, J. Org. Chem., 2013, 78, 2626.

3 E. Taxil, L. Bagnol, J. H. Horner and M. Newcomb, Efficient production of enol ether radical cations by heterolytic cleavage of beta-mesylate radicals, Org. Lett., 2003, 5, 827.

4 R. Paul and M. M. Greenberg, Mechanistic Studies on RNA Strand Scission from a C2'-Radical, J. Org. Chem., 2016, 81, 9199.

5 M. J. E. Resendiz, V. Pottiboyina, M. D. Sevilla and M. M. Greenberg, Direct strand scission in double stranded RNA via a C5-pyrimidine radical, J. Am. Chem. Soc., 2012, 134, 3917.

$6 \mathrm{~J}$. Stubbe and W. A. van der Donk, Protein Radicals in Enzyme Catalysis, Chem. Rev., 1998, 98, 705.

7 A. Abend, V. Bandarian, G. H. Reed and P. A. Frey, Identification of cis-ethanesemidione as the organic radical derived from glycolaldehyde in the suicide inactivation of dioldehydrase and of ethanolamine ammonia-lyase, Biochemistry, 2000, 39, 6250.

8 E. Taxil, L. Bagnol, J. H. Horner and M. Newcomb, Efficient production of enol ether radical cations by heterolytic cleavage of beta-mesylate radicals, Org. Lett., 2003, 5, 827.

9 J. H. Horner, E. Taxil and M. Newcomb, Laser Flash Photolysis Kinetic Studies of Enol Ether Radical Cations. Rate Constants for Heterolysis of $\alpha$-Methoxy- $\beta$-phosphatoxyalkyl Radicals and for Cyclizations of Enol Ether Radical Cations, J. Am. Chem. Soc., 2002, 124, 5402.

10 J. H. Horner and M. Newcomb, Enol Ether Radical Cation Reaction Kinetics. Laser Flash Photolysis Calibration of Radical Cation Clocks, J. Am. Chem. Soc., 2001, 123, 4364.

11 M. Newcomb, N. Miranda, M. Sannigrahi, X. Huang and D. Crich, Direct Measurement of Enol Ether Radical Cation Reaction Kinetics, J. Am. Chem. Soc., 2001, 123, 6445.

12 N. P. Schepp, Generation and absolute reactivity of an aryl enol radical cation in solution, J. Org. Chem., 2004, 69, 4931.

13 M. Schmittel, G. Gescheidt and M. Röck, The First Spectroscopic Identification of an Enol Radical Cation in Solution: The Anisyl-dimesitylethenol Radical Cation, Angew. Chem., Int. Ed. Engl., 1994, 33, 1961.

14 P. J. Kocienski, Protecting Groups, Georg Thieme, Stuttgart, 2005, ch. 2, p. 2.

15 B. M. Aveline, I. E. Kochevar and R. W. Redmond, Photochemistry of N-hydroxypyridine-2-thione derivatives: involvement of the 2-pyridylthiyl radical in the radical chain reaction mechanism, J. Am. Chem. Soc., 1995, 117, 9699.
16 M. M. Alam, A. Watanabe and O. Ito, Laser flash photolysis of dithio-2,2'-dipyridine; Structure and reactivity of pyridyl2-thio radical, J. Org. Chem., 1995, 60, 3440.

17 G. Bucher, Laser Flash Photolysis Study on N,N-Diethyl-2azidobenzylamine: The Reactivity of Iminoquinonemethides in Solution, Eur. J. Org. Chem., 2001, 2463.

18 (a) While 2-methylthiopyridine has been reported to show absorption slightly below $400 \mathrm{~nm}$ (see A. Albert, G. B. Barlin, Ionization Constants of Heterocyclic Substances. Part III. Mercapto-Derivatives of Pyridine, Quinoline, and Isoquinoline. J. Chem. Soc., 1959, 2384), this report likely is erroneous. Other publications do not mention this band (see, e.g., S. J. Dunne, L. A. Summers, E. I. von Nagy-Felsobuki, Conformational and Photoelectron Analysis of the Methylchalcogenopyridines, Phosph., Sulf. Silicon Rel. Elements, 1992, 72, 103); (b) S. Stoyanov, I. Petkov, L. Antonov, T. Stoyanova, P. Karagiannidis and P. Aslanidis, Thione-thiol tautomerism and stability of 2- and 4-mercaptopyridines and 2-mercaptopyrimidines, Can. J. Chem., 1990, 68, 1482.

19 G. Trampe, J. Mattay and S. Steenken, Ionisation of 1,3-dioxoles in aqueous solution by $248 \mathrm{~nm}$ laser flash photolysis characterisation of the radical cations, J. Phys. Chem., 1989, 93, 7157.

20 K. H. Lee, K.-L. Chin and S. Brumby, Electron spin resonance spectra of free radicals. Part 3. 2,2-Disubstituted 1,3-dioxolan-4-yl radicals, J. Chem. Soc., Perkin Trans. 2, 1985, 161.

21 D. G. Harman and S. J. Blanksby, Investigation of the gas phase reactivity of the 1-adamantyl radical using a distonic radical anion approach, Org. Biomol. Chem., 2007, 5, 3495.

22 C. Dietlin, X. Allonas, F. Morlet-Savary, J. P. Fouassier, M. Visconti, G. Norcini and S. Romagnano, Investigation of Barton Esters a Radical Photoinitiators, J. Appl. Polym. Sci., 2008, 109, 825.

23 M. J. Frisch, G. W. Trucks, H. B. Schlegel, G. E. Scuseria, M. A. Robb, J. R. Cheeseman, G. Scalmani, V. Barone, B. Mennucci, G. A. Petersson, H. Nakatsuji, M. Caricato, X. Li, H. P. Hratchian, A. F. Izmaylov, J. Bloino, G. Zheng, J. L. Sonnenberg, M. Hada, M. Ehara, K. Toyota, R. Fukuda, J. Hasegawa, M. Ishida, T. Nakajima, Y. Honda, O. Kitao, H. Nakai, T. Vreven, J. A. Montgomery Jr., J. E. Peralta, F. Ogliaro, M. Bearpark, J. J. Heyd, E. Brothers, K. N. Kudin, V. N. Staroverov, R. Kobayashi, J. Normand, K. Raghavachari, A. Rendell, J. C. Burant, S. S. Iyengar, J. Tomasi, M. Cossi, N. Rega, J. M. Millam, M. Klene, J. E. Knox, J. B. Cross, V. Bakken, C. Adamo, J. Jaramillo, R. Gomperts, R. E. Stratmann, O. Yazyev, A. J. Austin, R. Cammi, C. Pomelli, J. W. Ochterski, R. L. Martin, K. Morokuma, V. G. Zakrzewski, G. A. Voth, P. Salvador, J. J. Dannenberg, S. Dapprich, A. D. Daniels, Ö. Farkas, J. B. Foresman, J. V. Ortiz, J. Cioslowski and D. J. Fox, Gaussian 09, Revision D.01, Gaussian, Inc., Wallingford CT, 2009.

24 Y. Zhao and D. G. Truhlar, The M06 suite of density functionals for main group thermochemistry, thermochemical kinetics, noncovalent interactions, excited states, and transition elements: two new functionals and systematic testing of four M06-class functionals and 12 other functionals, Theor. Chem. Acc., 2008, 120, 215. 
25 A. D. Becke, Density-functional thermochemistry. III. The role of exact exchange, J. Chem. Phys., 1993, 98, 5648.

26 R. Ditchfield, W. J. Hehre and J. A. Pople, Self-Consistent Molecular Orbital Methods. 9. Extended Gaussian-type basis for molecular-orbital studies of organic molecules, J. Chem. Phys., 1971, 54, 724.

27 A. D. McLean and G. S. Chandler, Contracted Gaussianbasis sets for molecular calculations. 1. 2nd row atoms, $\mathrm{Z}=11-18, \mathrm{~J}$. Chem. Phys., 1980, 72, 5639.
28 T. H. Dunning Jr., Gaussian basis sets for use in correlated molecular calculations. I. The atoms boron through neon and hydrogen, J. Chem. Phys., 1989, 90, 1007.

29 J. Tomasi, B. Mennucci and R. Cammi, Quantum Mechanical Continuum Solvation Models, Chem. Rev., 2005, 105, 2999.

30 S. Miertuš, E. Scrocco and J. Tomasi, Electrostatic interaction of a solute with a continuum. A direct utilization of ab-initio molecular potentials for the prevision of solvent effects, Chem. Phys., 1981, 55, 117. 